\title{
PROCESSO DE REVITALIZAÇÃO URBANA: ECONOMIA CRIATIVA E DESIGN
}

THE PROCESS OF URBAN REVITALIZATION : CREATIVE ECONOMY AND DESIGN

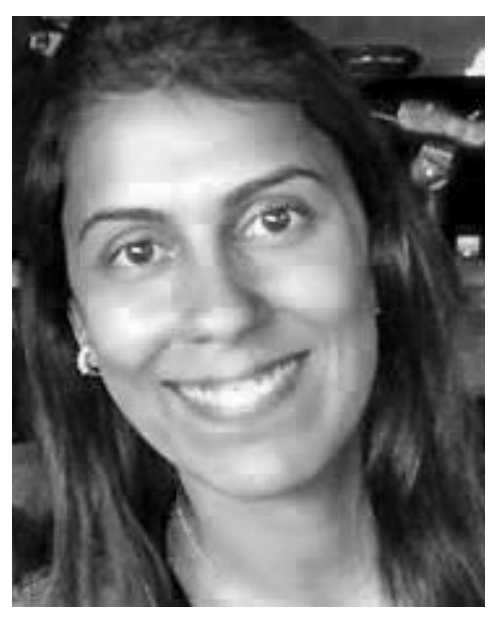

\section{Clarissa Stefani Teixeira}

Doutora em Engenharia de Produção pela Universidade

Federal de Santa Catarina

Departamento de Engenharia do Conhecimento -

Programa de Pós-Graduação em Engenharia e Gestão do

Conhecimento

clastefani@gmail.com

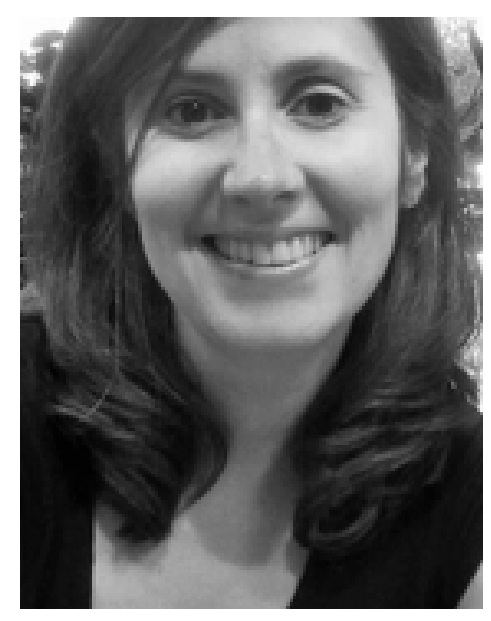

\section{Carmen Adán}

Doutora em Filosofia pela Universidade de Santiago de Compostela em 2002.

Coordenadora da Rede de Parques Científicos y Tecnológicos de Catalunya (Xarxa de Parcs Científics i Tecnològics de Catalunya, XPCAT), Barcelona, Espanha. mcadan@xpcat.net 


\section{LOGO}
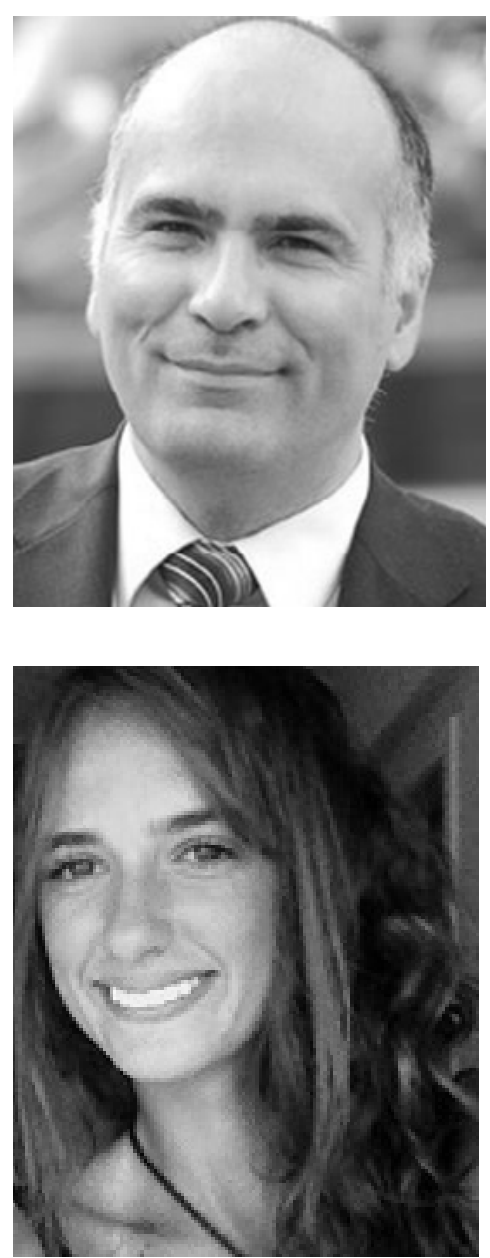

\section{Josep Miquel Piqué Huerta}

Mestre em Administração de Empresas pela ESADE Business and Law School e diploma da University of California Berkeley e do Instituto de Tecnologia de Massachusetts.

Presidente da Xarxa Parcs científics i Tecnològics de Catalunya (XPCAT) e da International Association os Science Parks and Areas of Innovation jmpique@technovabarcelona.org

\section{Jadhi Vincki Gaspar}

Graduanda em Ciências Contábeis na Universidade Federal de Santa Catarina

Pesquisadora ViA estação conhecimento

jadhivincki@hotmail.com 


\section{Resumo}

O presente artigo objetiva descrever como o processo de revitalização urbana alinhado a economia criativa pode servir de apoio para dar uma nova organização e um novo significado aos espaços urbanos que possuem áreas ociosas e em muitos casos degradadas, provendo da necessidade de projetos voltados às intervenções. Dessa forma, esse estudo demonstra que a revitalização urbana pode ser um meio para o fomento da criatividade e a promoção do desenvolvimento urbano, modelos como a cidade de Poblenou (Barcelona), Medellín (Colombia) e Soho (Londres) são exemplos dos efeitos positivos que a revitalização associada à economia criativa pode estimular.

\section{Palavras-chave}

Revitalização Urbana. Economia Criativa. Criatividade.

\section{ABSTRACT}

This article aims to describe how the urban revitalization process aligned the creative economy can serve as a support to give a new organization and a new meaning to urban spaces that have idle areas and in many degraded cases, providing the need for projects related to interventions. Thus this study shows that urban renewal can be a means for fostering creativity and the promotion of urban development models such as the city of Poblenou (Barcelona), Medellin (Colombia) and Soho (London) are examples of the positive effects that the revival associated with the creative economy can stimulate.

\section{Keywords}

Urban Revitalization. Creative economy. Creativity.

\section{INTRODUÇÃO}

Nascida, ou melhor, renascida a partir de grandes movimentos comerciais, a cidade se sofistica incessantemente ao acompanhar os grandes movimentos civilizatórios, culturais e econômicos da humanidade, esta se tornou agente ativo no estabelecimento das relações humanas a ponto de, neste século, deixar de ser palco inanimado, simples moldura ou contorno, para se tornar um de seus protagonistas, de base de negócios, transformando a si mesma em um grande negócio (VARGAS; CASTILHO, 2015). Em função de tornar a cidade o principal foco de mudança, nas últimas décadas, é visto a proliferação de políticas culturais e de revitalização para que as mesmas possam produzir 
efeitos de regeneração urbana com base no investimento estratégico nas artes, na cultura e na economia criativa (FERREIRA, 2010).

O processo de revitalização urbana se encaixa nesse contexto como um tema relativamente novo (TOLEDO, 2012), autores como Guerra et al (2005), propõem que o conceito de revitalização urbana seja entendido sobretudo como um ato que desenvolve estratégias e promove um processo com caráter inclusivo e integrador, capaz de provocar iniciativas para reverter processos de degradação física de determinados espaços, intervindo na melhoria da qualidade do ambiente como um todo. Já os autores Januzzi e Razente (2007) consideram a revitalização urbana uma nova postura de intervenção, que procura dar vitalidade às áreas por meio de uma série de atividades, levando em consideração questões econômicas, sociais, funcionais e ambientais, articulando as oportunidades, as vantagens competitivas e um urbano cada vez mais globalizado.

Realizar uma transformação na cidade é entendido como extrapolar suas fronteiras, suas ruas e limitações, pois se trata de um lugar de confluências, de interações e organizações sociais, de resistências, relações econômicas e afetivas. A cidade é um espaço de pluralidade, de fluxos contínuos, trocas simbólicas, possibilidades de sociabilidade ou de recolhimento, formações de novas narrativas e expectativas, luta pelo reconhecimento de seus direitos e de suas identidades. Trata-se, antes, de pensar em um tempo e espaço de interação e produção de transformações na cidade, visando o consumo ideológico, cultural, político e econômico de valorização do local, sendo um processo de performances de inovação e criatividade (BRASIL, 2011).

A relação entre criatividade e promoção do desenvolvimento urbano, o reconhecimento do peso e da importância das atividades culturais e criativas na promoção econômica e no desenvolvimento territorial, ou a procura da competitividade pela via da captação da famigerada "classe criativa" têm sido algumas das variantes mais destacadas deste interesse, traduzidas em abordagens e perspectivas múltiplas sobre esta questão (COSTA ET AL., 2007; COSTA ET AL., 2008), isto porque quando se fala de "classe criativa"é fundamental a conciliação entre capital humano e talentos para o desenvolvimento competitivo da economia criativa. Assim, para Florida e Tignali (2004), a competitividade futura vai depender dos "3 T's" do crescimento econômico, que são:Tecnologia, o Talento e a Tolerância, pois, segundo os mesmos autores, o fator determinante da competitividade global, já não se traduz simplesmente no comércio de bens e serviços ou nos fluxos de investimento e de capital, mas 
sim nos fluxos de pessoas. Na economia criativa global, os países bem sucedidos, serão aqueles com maior capacidade de atração, retenção e desenvolvimento de talentos criativos, aproveitando os seus recursos e capacidades criativas. Nesse sentido, o que se refere a intervenções direcionadas para a dinamização da economia urbana, têm se destacado as propostas fundamentadas no conceito de economia criativa, cujos desdobramentos são: a teoria dos clusters criativos e das cidades criativas centradas no campo da cultura e da inovação, e as intervenções que têm como base os estudos de resiliência urbana, nos quais as atividades de comércio e serviços apresentam-se como as principais protagonistas da requalificação das áreas urbanas (VARGAS; CASTILHO, 2015). Assim, diante dessa base teórica, esse estudo tem como principal objetivo conter informações que atrelam o processo de revitalização urbana, especialmente no apoio a presença de economia criativa e design.

\section{METODOLOGIA}

Esteestudoécaracterizadocomosendodescritivo(GODOY, 1995;VERGARA, 2000; PEREIRA, 2003), pois apresenta informações sobre o processo de revitalização urbana voltado principalmente para o fomento da economia criativa. Para a realização desse artigo, optou-se pelo desenvolvimento do conteúdo a partir da busca de dados por meio online diretamente nas homepages que reportam informações que acercam a concepção sobre a dimensão da revitalização urbana bem como por meio de análises que apresentem o conceito ou ainda estudos de revisão que abarcassem a proposta de revitalização urbana em prol da economia criativa. Também foram localizados documentos oficiais vinculados ao tema apresentado.

O trabalho exposto está dividido em cinco partes, incluindo a introdução, sendo seguidos por uma abrangência dos conceitos inerentes ao processo de revitalização urbana, englobando os tópicos de revitalização urbana atrelada à economia criativa e revitalização urbana com foco na valorização dos espaços por meio do design, completando com as experiências internacionais que enfocam a criatividade. Após essa visão será finalizado com as considerações finais. 


\section{DESENVOLVIMENTO}

\subsection{O processo de revitalização urbana}

O conceito da formação de uma região leva em consideração fatores técnicos, econômicos e culturais, ou seja, ao mesmo tempo em que uma região é uma paisagem natural, é também um espaço social, econômico, político e cultural (VIEIRA; SANTOS, 2012). Em maior ou menor escala as cidades estão se transformando, o crescimento das mesmas está acelerado, com isso, algumas cidades já alcançaram toda sua área e já não é mais possível encontrar espaços livres para construção. Da mesma forma, há problemas com cidades que cresceram sem atentar para o planejamento urbano e por isso começam a apresentar problemas no uso de algumas áreas, desvalorização de outros, mau uso e até abandono e marginalização de áreas (BEZERRA; CHAVES, 2014).

$\mathrm{O}$ ato de revitalizar, de acordo com Lima (2012), envolve um conjunto de operações destinadas a articular as intervenções pontuais de recuperação dos edifícios existentes em áreas degradadas, com as intervenções mais gerais de apoio à reabilitação das estruturas sociais, econômicas visando a consequente melhoria da qualidade de vida nessas áreas ou conjuntos urbanos degradados. Para os autores Bezerra e Chaves (2014) o termo de revitalização não é apenas remetido a uma ideia de restauração de Patrimônios Históricos Culturais, é um termo muito mais abrangente, pois trata de um total de ações, a fim de permitir a um determinado espaço nova eficiência, novo sentido em seu uso, visando uma melhoria do espaço e do seu entorno.

Seguindo esse pretexto, a reabilitação dos núcleos urbanos históricos é hoje assumida como um dos pilares na economia de usos e ocupações do solo, na rentabilização do espaço construído e na dotação de bens de utilidade pública. Precisamente no sentido da promoção da diversidade é vital a implementação de projetos estratégicos, especialmente através das áreas mais avançadas de formação e cultura, do ambiente urbano e dos espaços públicos, da investigação e tecnologia, e da economia baseada no conhecimento. Este entendimento pressupõe o reestabelecimento de centralidades dinâmicas e com identidade, quer a nível social, cultural e econômico, perante os novos contextos de afirmação dos territórios (MOURA ET AL., 2006).

Diante desse quadro, a intervenção urbana submetida à economia com foco na criatividade proporciona que o desenvolvimento do processo de revitalização urbana torne as cidades mais criativas. Assim a economia criativa é, portanto, a economia do intangível, do simbólico, ela se alimenta dos talentos criativos, 
que se organizam individual ou coletivamente para produzir bens e serviços criativos. A mesma se caracteriza pela abundância e não pela escassez, a nova economia possui dinâmica própria e, por isso, desconcerta os modelos econômicos tradicionais, pois seus novos modelos de negócio ainda se encontram em construção, carecendo de marcos legais e de bases conceituais consentâneas com os novos tempos (BOTELHO, 2011).

\subsection{Revitalização urbana atrelada à economia criativa}

A expressão economia criativa é relativamente recente, pois constitui produtos da terceira revolução industrial relacionados diretamente ao paradigma de produção da sociedade contemporânea baseada na era pós-industrial, pósfordista, do conhecimento, da informação e aprendizado (MIGUEZ, 2007). Porém, a crescente importância da cadeia da economia criativa nas últimas décadas motivou o aumento do interesse pela área, assim, surgiram estudos como de Costa e Santos (2011), os quais introduzem que o termo economia criativa tem como matéria-prima a criatividade, abrangendo atividades relacionadas ao design, moda, arquitetura, artes, produção cultural, cinema, turismo, mídia entre outros. Atrelado a isso, a Unesco $(2008,2010)$ coloca a economia criativa como forma de impulsionar o crescimento econômico e representar uma alternativa para o desenvolvimento, especialmente por ter como maior a ênfase a criatividade e poder utilizar características culturais e sociais de cada região como vantagens no desenvolvimento e produção de bens e serviços únicos competitivos.

Em termos genéricos, os benefícios da economia criativa podem ser encontrados por meio das seguintes ações (COSTA; SANTOS, 2011):

- Da criação de empregos, exportação, promoção e inclusão social, diversidade cultural e desenvolvimento humano;

- Do entrelaçamento entre economia, cultura e aspectos sociais com tecnologia, propriedade intelectual e objetivos turísticos;

- De um sistema econômico baseado no conhecimento desenvolvendo a dimensão e através da interligação entre elementos macro e micro da economia; - Do desenvolvimento da inovação através de políticas multi-economia criativa: novas oportunidades baseadas no capital intelectual.

As cidades sempre foram decisivas para o desenvolvimento econômico e social (SOJA, 2000), para proporcionar um espaço que através da revitalização urbana englobe uma economia com foco na criatividade, ressalta-se economia criativa a partir das dinâmicas culturais, sociais e econômicas construídas a partir do 
ciclo de criação, produção, distribuição/circulação/difusão e consumo/fruição de bens e serviços oriundos dos setores criativos, como representativos dos diversos conjuntos de empreendimentos que atuam no campo da economia criativa. Assim, consideram-se setores criativos aqueles cujas atividades produtivas têm como insumos principais a criatividade e o conhecimento. Chega-se então à seguinte conclusão: setores criativos são todos aqueles cujas atividades produtivas têm como processo principal um ato criativo gerador de valor simbólico, elemento central da formação do preço, e que resulta em promoção de riqueza cultural e econômica do ambiente (BOTELHO, 2011). A figura 1. ilustra a economia criativa e a dinâmica de funcionamento dos seus elos:

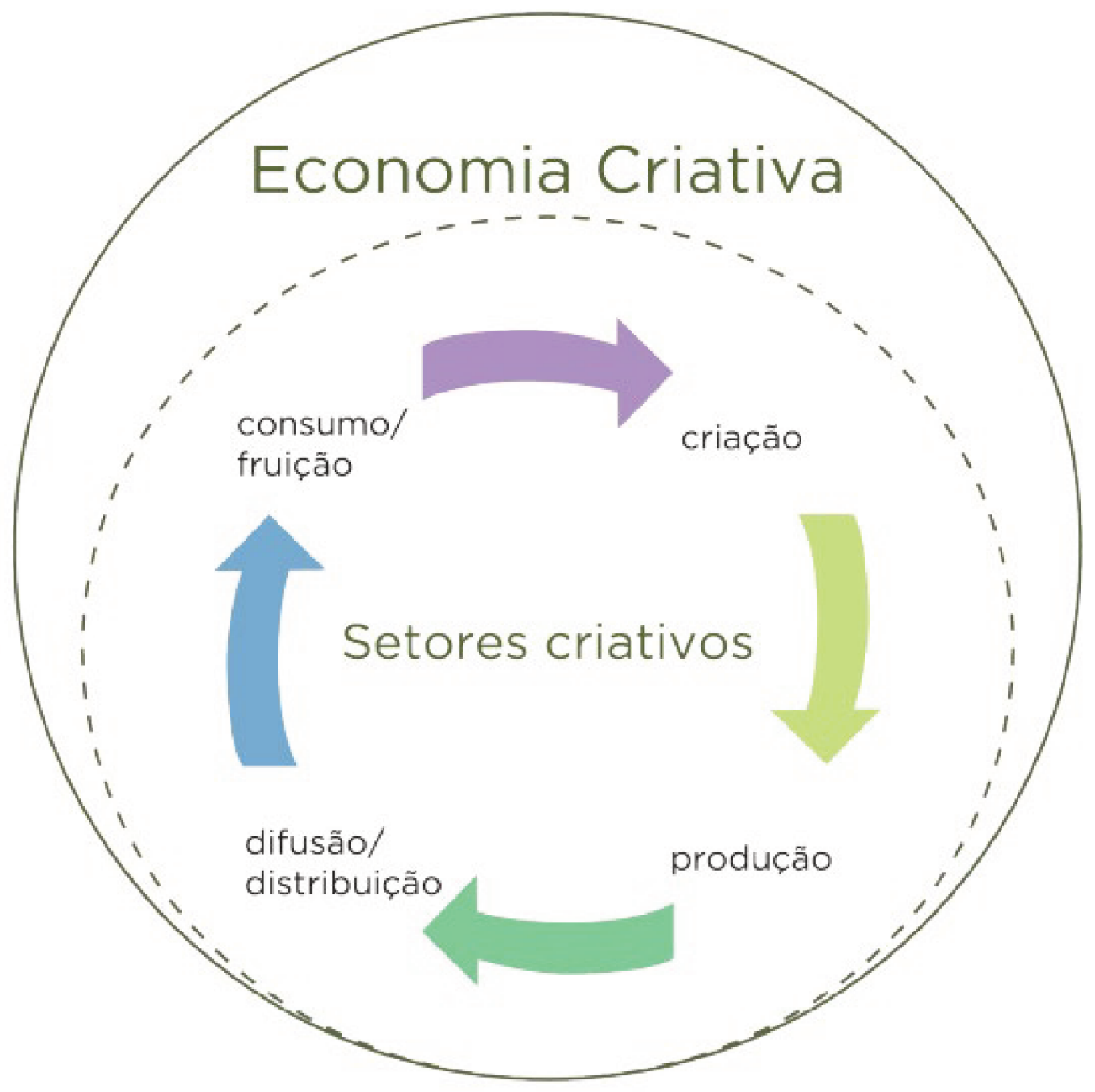

Figura 1. Economia criativa e a dinâmica de funcionamento dos seus elos. Fonte: Botelho, 2011. Disponivel em: <http://www.viacultural.org.br/site/wp-content/uploads/2012/08/livroportuguesweb.pdf\#page $=80>$. 
Atualmente, a emergência ou o ressurgimento do protagonismo das cidades está vinculado a diferentes perspectivas, desde a economia do conhecimento e competitividade à economia criativa (VALE, 2007). À vista disso, como as cidades estão em constantes mudanças, torna-se relevante a extensão de idéias e planos de ocupação dos territórios. Assim, associar o processo de revitalização com a economia criativa permite o desenvolvimento de mudanças nos espaços urbanos de modo que as transformações físicas possam ser integradas à cidade conduzindo o estimulo a atividades econômicas, sobretudo na área criativa. Conjuntamente, Glaeser (2000) sustenta que as cidades são verdadeiros centros de criação e transmissão de idéias, assim, inúmeras intervenções urbanas de reabilitação, requalificação e regeneração urbana têm seguido uma estratégia focada na criatividade e cultura, destacando-se a revitalização dos centros históricos, a promoção de bairros culturais e dinamização de espaços industriais descativados (ANDRÉ; VALE, 2012). Portanto, é salientado então a crescente relevância econômica e social das atividades criativas nas cidades, que propiciam a criação de formas intangíveis de capital simbólico e cultural na cidade e a formação de uma imagem de inovação e criatividade, dinamismo e mudança, indispensáveis para a atração de potenciais investidores (CASTELLS, 1996). Deste modo, para que a haja um crescimento inteligente, sustentável e inclusivo é inserido o modelo quadruple hélix, o qual promove a sinergia entre indústria, governo, universidades e mercado, isto porque a criatividade e inovação colocadas ao serviço do desenvolvimento estratégico das cidades representam assim um desafio para as autoridades públicas, pelo fato de implicarem com o próprio sistema de governação local, não serão apenas as autoridades locais que terão o papel de "fazer" a cidade criativa, mas elas em cooperação com a comunidade, as empresas e as universidades (GONÇALVEZ, 2013).

Para Landry (2000) e Florida (2002), as cidades precisam atrair a nova "classe criativa" de forma a ampliar os seus níveis de competitividade. É neste contexto que o processo de revitalização urbana é levado em consideração para difundir o discurso de promoção da economia criativa como estratégia, primeiro entre as instituições internacionais e governos nacionais e, posteriormente, entre as administrações regionais e locais como uma possível resposta à recessão (PRATT, 2009). 


\subsection{Revitalização urbana: valorização dos espaços por meio do design}

A mudança surge como mais do que uma necessidade, uma fatalidade inerente ao advento de uma era globalizada, onde a informação e o conhecimento surgem como os principais elementos difusores do período pós-industrial e pós-moderno, desvinculando-se da lógica linear de como o design era entendido até então (ROCHA, 2014). Segundo o autor Kruken et al. (2009) o design tem vindo a adotar novas abordagens de atuação ao longo dos anos e essa mudança reflete-se quer nas próprias ferramentas que utiliza, quer nas próprias pessoas que o praticam. Será neste sentido que o Design, em conjunto com diferentes atores, e tendo em conta a sua capacidade criativa e dinâmica, poderá servir de motor para a construção de ferramentas que a longo prazo poderão contribuir para a disseminação de preceitos ligados à revitalização urbana (ROCHA, 2014).

Desde há alguns anos, as áreas centrais começaram a ser vistas pelo governo federal e pelos governos municipais como locais de oportunidade para geração de atividades e receitas, assim como produção habitacional (BIDOUZACHARIASE, 2006). Está cada vez mais frequente a discussão entorno de políticas públicas que visam à recuperação de áreas urbanas que se encontram em processo de deterioração. Para os autores Dos Anjo e De Lima (2008) o processo de revitalização urbana se encaixa a esse contexto como o ato que irá desencadear o revigoramento das pessoas, suas relações com o espaço em que vivem, com as instituições em sua volta e com elas mesmas. Desta forma, isso requer partir do conhecimento do que é real/concreto e rearticular com um todo, ainda que desconhecido e fragmentado. Deve-se pensar na possibilidade de se intervir nessa realidade conhecida, provocar aquelas mudanças desejadas pelos os que vivem o seu dia a dia.

Já de acordo com Bezerra e Chaves (2014) a palavra revitalização sempre traz à mente a idéia de conjuntos de medidas e ações que surgem com o objetivo de aplicar a determinada área um novo valor, dando-lhe vida econômica e social. Assim sendo, em relação à economia, ao assumir o comércio como atividade econômica predominante no centro das cidades, este deverá funcionar como um catalisador da revitalização socioeconômica desses núcleos, havendo a necessidade estratégica de procura de soluções para a sua dinamização e revitalização enquanto unidades econômicas (BARRETA, 2009). Logo, o design, enquanto instrumento de conexão cultural e, tendo em conta a sua capacidade de atuação sistémica, é uma disciplina capaz de instituir no tecido comercial 
tradicional novos atributos estratégicos, que de certa forma, potencializam a sua regeneração e promovem a sua reaproximação com o público por meio da criação de novas práticas e valores que visam potenciar a sua natureza comercial (ROCHA, 2014).

Neste sentido, deve-se procurar estabelecer um vínculo entre o entendimento dos valores sociais, econômicos e políticos que incidem nas cidades (FRENKEL, 2008). Segundo Villota (2001), o desenho urbano deve apontar as potencialidades e converter limitações em oportunidades para aproveitar e promover o contato social, a vitalidade comercial e a eficiência da cidade, devem-se conjugar interesses e vontades daqueles que atuam na cidade, como os setores públicos e privados, comunidades organizadas e usuários.

\subsection{Revitalização urbana com enfoque na criatividade: experiências internacionais}

Nos últimos 30 anos, o processo de revitalização urbana atingiu diversos países que voltaram sua atenção à recuperação de áreas abandonadas, principalmente aquelas de cunho histórico. Autores como Piqué e ParejaEastaway $(2013$, p. 2) citam que as cidades se tornaram nós de competitividade no plano internacional, pois são nelas que a inovação ocorre e contribui para um melhor desempenho econômico dos territórios e melhor qualidade de vida do cidadão. Certos modelos reconhecidos internacionalmente como o 22@Barcelona (Barcelona - Espanha), o Ruta N (Medellin - Colombia) e Soho (Londres - UK), são considerados como experiências com alto desempenho na elaboração de estratégias para estimular a inovação, o conhecimento e a criatividade no território.

Em uma análise histórica, de acordo com Pique et. al (2008, p. 7), desde 2000, a Câmara Municipal de Barcelona tem trabalhado para transformar Poblenou, um bairro com vocação produtiva, considerado o antigo distrito industrial têxtil de Barcelona em um novo distrito inovador englobando universidades, centros de pesquisa e indústrias de conhecimento, bem como instalações públicas e sociais. Logo, o projeto 22@Barcelona (figura 2) foi considerado uma oportunidade única para converter o que há mais de cem anos era o seu principal motor econômico,mas que se encontrava em condições obsoletas, em um espaço urbano que envolve um novo modelo de conhecimento,que incentiva a colaboração e sinergias entre a tríplice hélice (universidade, governo e empresas) com o objetivo de desenvolver a inovação e o empreendedorismo, juntamente com a implantação de uma boa qualidade de vida para os seus 
cidadãos. Conforme os autores Pareja-Eastaway e Pique (2011) este projeto não é meramente um plano de planejamento, pois sinalizou uma nova forma de compreender a cidade, e pode ser entendido como uma peça central do grande projeto do município de Barcelona: "Barcelona, cidade do conhecimento", cujo principal objetivo é transformar o que costumava ser o paradigma da sociedade industrial em uma sociedade do conhecimento, em especial em atividades de nova aeracão relacionadas com educacão. criatividade e inovacão.

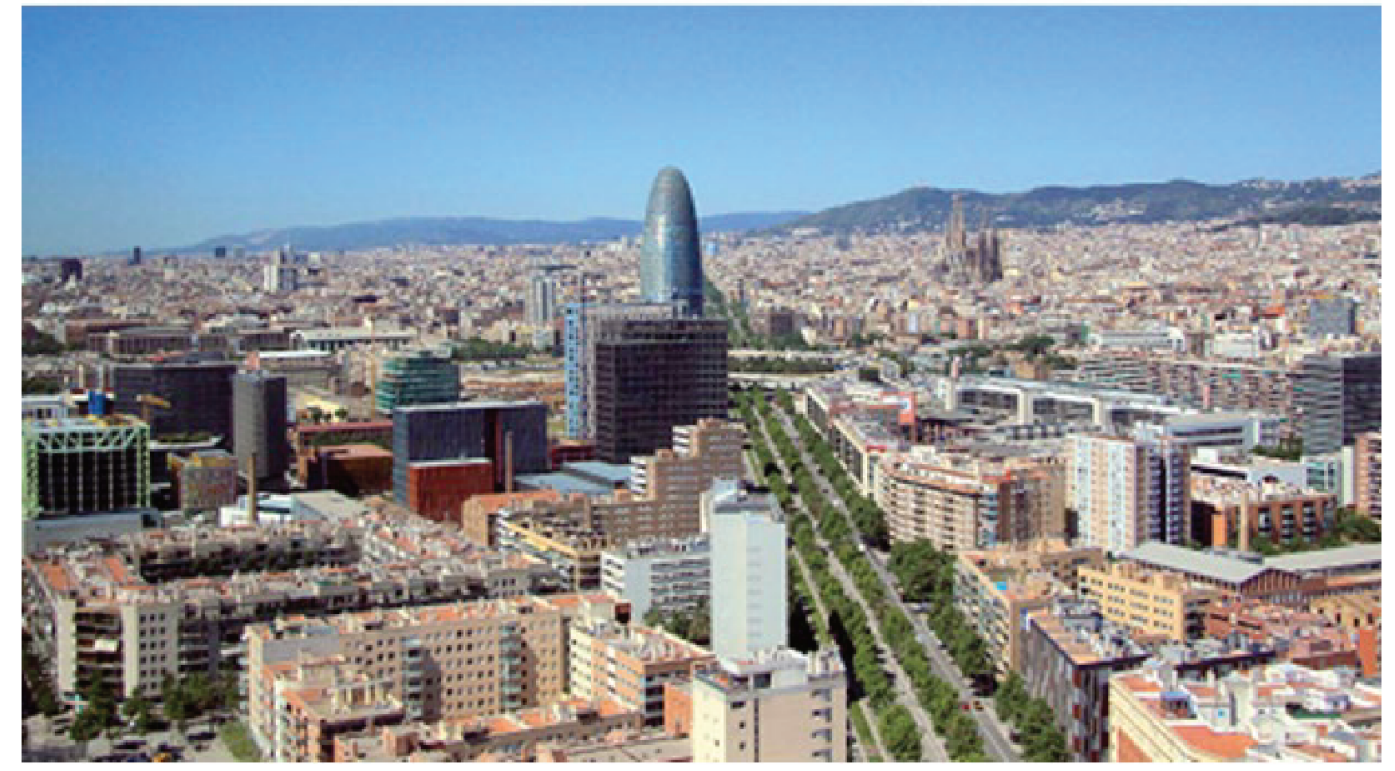

Figura 2. Vista de Barcelona incluindo a área do projeto 22@. Disponível em: <http://premsa. firabarcelona.com/SALONS\%20-\%20SHOWS/Alimentaria\%20Barcelona\%20(2014)/Barcelona/>.

Medellín é a segunda maior cidade da Colômbia, em 1991, a mesma era considerada a cidade mais violenta do mundo, com 381 mortes por 100 mil pessoas, com isso, a cidade era diretamente associada a drogas e violência, porém atualmente, Medellín não é mais a cidade mais violenta do mundo, nem ao menos da Colômbia ou da América Latina. A cidade colombiana é sinônimo de transformação, transparência, educação, cultura e otimismo (REIS, 2011). Como parte do retorno positivo, no ano de 2012, Medellín (figura 3) foi eleita a cidade mais inovadora do mundo em uma competição realizada pela ONG americana Instituto Urban Lande. Em 2016, a capital de Antioquia é a vencedora do Prêmio Cidade Lee KuanYew World 2016, um prêmio que reconhece as cidades do mundo que conseguem se transformar rapidamente (SEMANA, 2016). Portanto, a criatividade se dá no compromisso de mudança política e governamental da cidade, isso porque, a cidade se torna criativa ao 
dar vazão a um conjunto de condições, por meio das quais pequenos atos podem acontecer e vão se somando mais rápido do que os problemas que lhes fazem de contraponto (REIS. 2011).

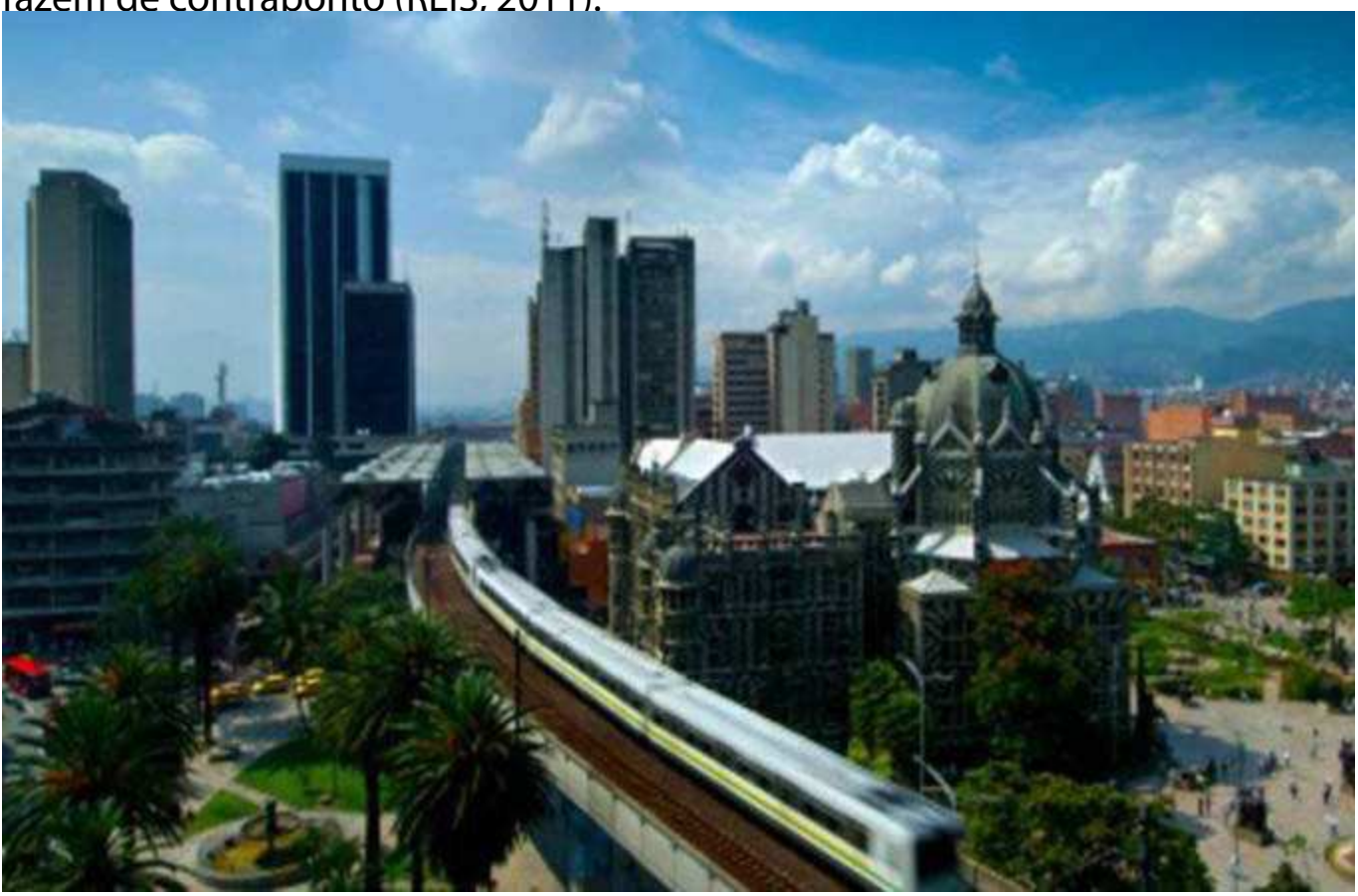

Figura 3. Vista da Cidade de Medellín. Disponível em: <http://exame.abril.com.br/mundo/ noticias/medellin-e-santiago-sao-as-melhores-cidades-para-viver-na-al>.

Atualmente o bairro Soho (figura 4), em Londres, tem sido o local preferido por várias pequenas empresas que trabalham nos empreendimentos cinematográficos e na mídia. Durante a década de noventa, um grupo de pequenas empresas de efeitos especiais se uniu para pressionar a BT Group, a principal empresa de telecomunicações do Reino Unido, a instalar uma rede de banda larga no centro de Londres para que todos conseguissem trabalhar coletivamente em projetos que fossem impossíveis de fazer individualmente. Assim, esta foi a origem da rede Sohonet, que permitiu desde então que empresas pequenas constituíssem um consórcio capaz de competir pelos grandes contratos na área das imagens geradas por computador (IGC) para aos estúdios de Hollywood. Pouco tempo depois, fundou-se a CFC Framestore, um dos maiores e grandes projetos de IGC do mundo, que atualmente emprega centenas de pessoas talentosas, também sediada no Soho (NEWBIGIN, p. 37, 2010). Partindo-se, então, do princípio desse contexto histórico, percebe-se que os setores criativos vão além dos setores denominados como tipicamente 
culturais ligados à produção artístico-cultural (música, dança, teatro, ópera, circo, pintura, fotografia, cinema), compreendendo outras expressões ou atividades relacionadas às novas mídias, à indústria de conteúdos, ao design, à arquitetura entre outros (BOTELHO, 2011).

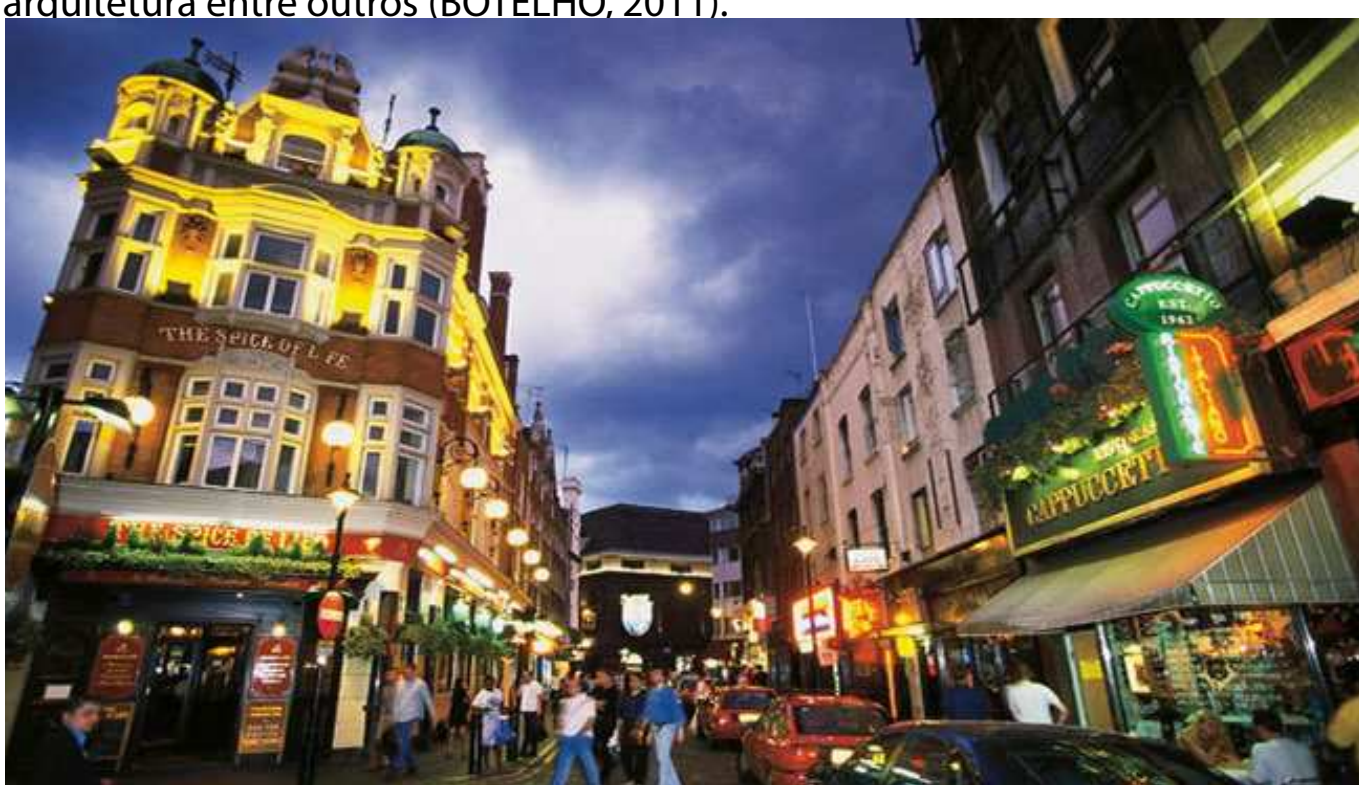

Figura 4. Bairro Soho. Disponível em: <http://destinolandia.com/el-soho-el-barrio-masestimulante-de-londres/>.

\section{CONSIDERAÇÕES FINAIS}

Com o crescimento das cidades, com constantes transformações, diferentes áreas perdem visibilidades, são degradadas pelo mau uso ou pela má administração pública (BEZERRA; CHAVES, 2014). Com isso, é importante que fique clara a compreensão que revitalização urbana compreende a necessidade de ações que visam a reconfiguração ou atribuição de um novo sentido ao uso de uma área degradada, que apresenta uma subutilização ou começa a tornase obsoleta.

Tendo em conta esta realidade, é valido ressaltar que a dimensão do processo de revitalização urbana busca as áreas por meio de uma série de atividades, levando em consideração questões econômicas, sociais, funcionais e ambientais, no quesito economia criativa. Segundo os autores Landry e Bianchini (1995) a criatividade se adequa a esse meio como um processo através do qual as novas ideias são produzidas, enquanto a inovação é o processo por meio do qual elas são implementadas. Todavia, as cidades podem ser muito criativas, mas podem 
não ter as habilidades analíticas, avaliativas e financeiras para o desenvolvimento de soluções inovadoras. Nesse caso, o papel do Design reúne a proposta uma série de valências transversais ao campo da habilidade projetual, visando mais do que isso, a conceção de estratégias integradas que viabilizem a construção de suportes diferenciadores e que possibilitem por exemplo, a longo prazo, a regeneração do comércio local das cidades atuais (ROCHA, 2014).

No âmbito internacional, lugares como o 22@Barcelona na Espanha, o Ruta Medellín na Colômbia e Soho em Londres, são consideradas experiências com alto desempenho na elaboração de estratégias para estimular a inovação, o conhecimento e a criatividade no território em decorrência da revitalização urbana realizada nesses locais. Segundo Bezerra e Chaves (2014) a paisagem urbana pode sofrer diferentes tipos de intervenções, cada uma com sua característica, e para uma compreensão exata do que é possível infligir à paisagem, objetivando diferentes resultados. Atrelado a isso, é nítida em ambos os casos a importância da conexão da revitalização com a economia criativa e o design para o desenvolvimento urbano.

\section{REFERÊNCIA BIBLIOGRÁFICA}

ANDRÉ, I.; VALE, M. A Criatividade Urbana na Região de Lisboa. CCDR-LVT, Lisboa, 2012.

\section{BARRETA, J. Prospectiva e Planeamento. Centros Comerciais a Céu Aberto}

- Potencialidades da gestão integrada de centros urbanos, vol. 16, 34 p., 2009, Disponível em: <URL:http://www.dpp.pt/pages/files/prosp_plan_16.pdf>. Acesso em: 10 de agosto de 2016.

BEZERRA, A. M. M.; CHAVES, C. R. C. Revitalização Urbana: Entendendo o processo de requalificação da paisagem. Revista do CEDS- Periódico do Centro de Estudos em Desenvolvimento Sustentável da UNDB, n. 1, 2014.

BIDOU-ZACHARIASEN, C. De volta à cidade: dos preocessos de gentrificação ás políticas de" revitalização" dos centros urbanos. Annablume, 2006.

Botelho, I. Criatividade em pauta: alguns elementos para reflexão. PLANO DA SECRETARIA DA ECONOMIA CRIATIVA, 2011. 
BRASIL, M. Plano da Secretaria da Economia Criativa-Políticas, diretrizes e ações 2011 a 2014. Brasília: Ministério da Cultura, 2011.

CASTELLS, M. The Rise of the Network Society. Blackwell: Oxford, 1996.

COSTA, D.; SANTOS, S., E. D. Economia criativa: novas oportunidades baseadas no capital intelectual. Economia \& Tecnologia, Curitiba, 2008.

COSTA, P. ET AL. 0 meio urbano e a génese da criatividade nas actividades culturais, In: Recriar e valorizar o território. Actas do $13^{\circ}$ congresso da APDR, Açores, Coimbra: APDR 2744, 2007.

COSTA, P.ET AL.On'creative cities' governance models: a comparative approach. The Service Industries Journal, 28:3, 393 - 413, 2007.

DOS ANJOS, E. E.; DE LIMA, M. H. T.. Revitalizar o Centro de Vitória (ES), 2008.

FERREIRA, C. Cultura e regeneração urbana: novas e velhas agendas da política cultural para as cidades. Revista Tomo, 2010.

FIORIDA, R. The Rise of the Creative Class, and How it's Transforming Work, Leisure, Community and Everyday Life. Basic Books: New York, 2002.

FLORIDA, R.; TINAGLI, I. Europe in the Creative Age. s.I.:DEMOS, 2004.

FRENKEL, D. B. A revitalização urbana e as viagens a pé: uma proposta de procedimento auxiliar na análise de projetos, 2008.

GLAESER, E. L. The new economics of urban and regional growth. In: Clark G, Feldman M, Gertler M (eds) The Oxford Handbook of Economic Geography, Oxford University Press, Oxford: 83-98, 2000.

GUERRA et al. Políticas Públicas de Revitalização Urbana-Revitalização para a formulação estratégica e operacional das actuações a concretizar no QREN. ISCTE/CET, Observatório do QCA III, 2005.

GODOY, A. S. Introdução a pesquisa qualitativa e suas possibilidades. Revista 
de Administração de Empresas, v. 35, n. 2. 1995.

Gonçalves, J.V.C. I. Processos de elaboração de criatividade, inovação e capital social: O caso de Almada", Revista Crítica de Ciências Sociais, 99, pp. 73-98, 2013. (ISSN: 0254-1106; elSSN: 2182-7435)

JANUZZI, D. C. R.; RAZENTE, N. Intervenções urbanas em áreas deterioradas. Semina: Ciências Sociais e Humanas, v. 28, n. 2, p. 147-154, 2007.

KRUKEN, Lia. Design e Território - Valorização de identidades e produtos locais. Studio Nobel, 2009.

LANDRY, Charles e BIANCHINI, Franco. The creative city. Londres: Demos, 1995. Disponível em: $<$ http://www.demos.co.uk/files/thecreativecity.pdf $>$. Acesso em: 10 de agosto 2016.

Lima, M. S. (2012). Revitalização Urbana Proposta Teatro Mindelo.

MIGUEZ, P. Economia criativa: uma discussão preliminar. In: Nussbaumer, G. M. (Org.). Teorias e políticas da cultura: visões multidisciplinares. Salvador: EDUFBA. Coleção CULT, p. 96-97, 2007.

MOURA ET AL. A revitalização urbana: Contributos para a definição de um conceito operativo. Cidades, Comunidade e Territórios, n 12/13, p. 15-34, 2006.

NEWBIGIN, J. A economia criativa: um guia introdutório. London: Reino Unido: ๔) British Council - Unidade de Economia Criativa, 2010.

PAREJA-EASTAWAY, M.; PIQUÉ, J. M. Urban regeneration and the creative knowledgeeconomy:The case of 22@in Barcelona.Journal of Urban Regeneration \& Renewal, v. 4, n. 4, p. 319-327, 2011.

PEREIRA, M. G. Epidemiologia:Teoria e Prática. Rio de Janeiro: Koogan, 2003.

PIQUÉ ET AL. Barcelona22@: a knowledge city beyond science parks. Anais: IASP World Conference on Science and Technology Parks. 26., USA. 2008. p. 1-4.

PIQUÉ, J. M. PAREJA-EASTAWAY, M. Knowledge Cities on Smart Cities: transferring the 22@Barcelona model. Anais: IASP World Conference on Science and Technology Parks. 30., 2013. 
PRATT, A. The cultural contradictions of the creative city. City, Culture and Society, 2011.

REIS, A. C. F.; KAGEYAMA, P. Cidades criativas: perspectivas. São Paulo: Garimpo de Soluções, 2011.

ROCHA, Raphaella Fischer. O papel do design na revitalização dos centros urbanos comerciais: a Rua Direita em Aveiro, como caso de estudo, 2014.

SOJA, E. W. Postmetropolis. Critical Studies of Cities and Regions. Blackwell, Oxford, 2000.

TOLEDO, M. P. de. Participação de instituições locais em projetos de revitalização urbana: o caso do projeto Porto Maravilha na cidade do Rio de Janeiro, 2012.

UNESCO. Creative economy: report 2008. Nova York: United Nation, 2008.

UNESCO. Creative economy: report 2010. Nova York: United Nation, 2010.

VALE, M. Globalização e competitividade das cidades: uma crítica teórica na perspectiva da política urbana. In: AA. VV. (eds.) Geophilia. O Sentir e os Sentidos da Geografia, Centro de Estudos Geográficos, Lisboa: 465-474, 2007.

VARGAS, H. C.; De CASTILHO, A. L. H. (2015). Intervenções em centros urbanos: objetivos, estratégias e resultados. Editora Manole.

VERGARA, S. C. Projetos e relatórios em administração. São Paulo: Atlas, 2000.

VILLOTA, J, "Urbanismo, Planificación y Diseño. La Ciudad y sus Disciplinas". Entorno Urbano 1999 - 2001. Maestria en Diseño Urbano. Universidade Metropolitana, Venezuela, 2001. 
Josep M. Piqué é IASP Presidente -International Associação de Parques e Áreas de inovação- Ciência. Engenheiro de Telecomunicações de La Salle e UPC, Mestre em Administração de Empresas pela ESADE e diploma da UC-Berkeley e do Instituto de Tecnologia de Massachusetts (MIT). Durante seu tempo em La Salle-URL, de 1997 a 2007, ele promoveu a criação de La Salle Technova e foi responsável pela pós-graduação e programas de mestrado e transferência de tecnologia. Em fevereiro de 2009 ele se juntou a Comissão de HIT Barcelona até Junho de 2010. Diretor do escritório do crescimento econômico da cidade de Barcelona. Director de setores estratégicos e inovação em Barcelona ativa, CEO a 22 @ Barcelona. CEO da Salle Technova Barcelona dese setembro 2015 até 2016. O vice-presidente da Associação de Ciência e Tecnologia Parques de Espanha (APTE) 2012-2016, durante este mesmo período foi Presidente Conselho de Ciência e Tecnologia (CTecno) e Xarca Parcs científics i Tecnològics de Catalunya (XPCAT). De 20142016 foi Vice-Presidente da IASP.

Carmen Adán tem Licenciatura em Filosofia pela Universidade de Santiago de Compostela em 1989. Doutora em Filosofia pela Universidade de Santiago de Compostela em 2002. Coordenadora da Rede de Parques Científicos y Tecnológicos de Catalunya (Xarxa de Parcs Científics i Tecnològics de Catalunya, XPCAT), Barcelona, Espanha.

Clarissa Stefani Teixeira é Pós-Doutora pela UFSC. Doutora em Engenharia de Produção pela mesma instituição. Tem formação tutorial em Educação a Distância pela UFPR e experiência profissional na docência do ensino à distância atuando no Portal Educação, IFSC e Fundação Getúlio Vergas (FGV). Tem experiência no ensino superior e pós-graduação em Instituições como: SOCIESC, FGV, ASSESC, ISEPE e Instituto de Orientação Profissional e de Carreira. Na área científica possui mais de 100 artigos publicados e é revisora de 14 periódicos nacionais e internacionais. Coordenou a área de pesquisa, extensão e trabalho de conclusão de curso da Faculdade SOCIESC - Unidade Florianópolis. Tem experiência em elaboração e gestão de projetos com órgãos de fomento e financiamento como: Banco Interamericano de Desenvolvimento (BID) e Banco Nacional de Desenvolvimento Econômico e Social (BNDES). Como Gerente 
de Ciência, Tecnologia e Inovação do Governo do Estado de Santa Catarina Secretaria de Desenvolvimento Econômico Sustentável (SDS) atuou como gestora de projetos em âmbito Estadual e elaboração da Política Estadual de CT\&I. Em meio empresarial teve atuação em inovação, tecnologia, usabilidade e ergonomia. Atuou como supervisora geral da reformulação do Portal do Professor ? parceria UFSC e Ministério da Educação. Atua na implantação dos 13 Centros de Inovação do Estado de Santa Catarina (SDS-RECEPETi-UFSC). É professora Adjunta do Departamento de Engenharia do Conhecimento Centro Tecnológico da Universidade Federal de Santa Catarina (UFSC). É líder do Grupo de Pesquisa em Habitats de Inovação e Empreendedorismo da UFSC - VIA Estação Conhecimento (via.ufsc.br).

Jadhi Vincki Gaspar Graduanda em Ciências Contábeis pela Universidade Federal de Santa Catarina e membro do grupo de pesquisa VIA Estação Conhecimento (http://via.ufsc.br/) pela mesma universidade. Tem experiência em administração com foco em contabilidade, habitats de inovação, revitalização urbana, empreendedorismo e redes de colaboração.

Recebido em: 17/08/2016

Aceito em: 07/10/2016 